\title{
Teor, rendimento e composição química do óleo essencial de manjericão sob doses de cama de frango
}

\author{
José Magno Q Luz'; Tatiane PS Morais ${ }^{1}$; Arie F Blank²; Ana Carolina B Sodré1; Guedmiller S Oliveira ${ }^{1}$ \\ ${ }^{1}$ UFU-ICIAG, C. Postal 593, 38400-902 Uberlândia-MG; ${ }^{2}$ UFS-Dep ${ }^{\text {to }}$ Eng. Agronômica, Av. Marechal Rondon, s/n, Jardim Rosa Elze, \\ 49100-000 São Cristóvão-SE; jmagno@umuarama.ufu.br
}

\begin{abstract}
RESUMO
Óleo essencial de manjericão (Ocimum basilicum L.) com alta concentração de linalol é valorizado no mercado internacional e amplamente usado nas indústrias de condimentos e cosméticos. Há poucas informações a respeito do cultivo de manjericão e, portanto o presente trabalho teve o objetivo de avaliar o teor, o rendimento e a qualidade de óleo essencial de genótipos de manjericão em função de níveis de adubação orgânica com cama de frango nas condições de inverno sob irrigação. O experimento foi conduzido na Fazenda Experimental do Glória, pertencente à Universidade Federal de Uberlândia. Foram testados cinco níveis de adubação, sendo $2 ; 4 ; 6$; 8 e $10 \mathrm{~kg}$ de cama de frango por $\mathrm{m}^{2}$. O delineamento experimental utilizado foi de blocos ao acaso em esquema fatorial $5 \times 2$, com quatro repetições. Foram semeados os genótipos Manjericão PI 197442-S3 (G1) e Manjericão NSL 6421-S3 (G2). O óleo essencial foi extraído por hidrodestilações com aparelho tipo Clevenger modificado. Avaliou-se a altura da planta; comprimento e largura de folha; relação comprimento/largura $(\mathrm{C} / \mathrm{L})$; teor e rendimento de óleo essencial, e teor de linalol no óleo essencial extraído de folhas e inflorescências frescas e secas. As doses de adubo influenciaram significativamente o teor de linalol do óleo essencial destilado a partir de parte aérea fresca e seca dos genótipos 1 e 2 . As outras variáveis não apresentaram diferenças significativas.
\end{abstract}

Palavras-chave: Ocimum basilicum, planta aromática, adubo orgânico.

\begin{abstract}
Content, yield and chemical composition of the essential basil oil under chicken manure levels

Basil (Ocimum basilicum L.), essential oil with high linalool content, is appreciated in the international market and widely used in spice and cosmetics industries. There are few informations available for basil cultivation, and therefore, the aim of this work was to evaluate the content, yield and quality of the essential oil of basil genotypes depending on organic fertilizer levels in the winter and using irrigation. The experiment was carried out in the Universidade Federal de Uberlândia. Five fertilizer levels were evaluated: 2; 4; $6 ; 8$ and $10 \mathrm{~kg}$ of chicken manure per $\mathrm{m}^{2}$. A completely randomized blocks design in factorial scheme was used with four replications. Two basil genotypes were sown: PI 197442-S3 (G1) and NSL 6421S3 (G2). Hydrodistillation with a modified Clevenger was realized for essential oil extraction. We evaluated the plant height; length and width of leaves; length/width relation $(\mathrm{C} / \mathrm{L})$; content and yield of essential oil; and linalool content in the essential oil extracted from fresh and dry leaves and flowers. The chicken manure levels had significantly influenced the linalool content in the distilled essential oil from fresh and dry leaves and flowers of both genotypes. The other variables did not present significant difference.
\end{abstract}

Keywords: Ocimum basilicum, aromatic plant, organic fertilizer.

(Recebido para publicação em 13 de junho de 2008; aceito em 14 de agosto de 2009)

(Received in June 13, 2008; accepted in August 14, 209)

$\mathrm{O}$ óleo essencial de manjericão (Ocimum basilicum L.) com alta concentração de linalol é valorizado no mercado internacional e amplamente usado nas indústrias de condimentos e cosméticos (Carvalho Filho et al., 2006). O manjericão, também conhecido como alfavaca, basilicão, pertence à família Lamiaceae, é uma planta originária da Ásia tropical e tem preferência por climas quentes a amenos (Lorenzi \& Matos, 2002). Entre as ervas aromáticas, o manjericão possui importância econômica no Brasil na obtenção de óleo essencial, sendo seu consumo tanto in natura quanto para processamento industrial. Seu óleo é muito apreciado na culinária, na aromatização de alimentos e bebidas, e poderá ser usado nas indústrias de cosméticos e perfumarias. Apresenta propriedades inseticidas, repelentes, antimicrobianas, sendo também utilizado na conservação de grãos (Fernandes, 2004).

O conteúdo de óleo essencial pode variar consideravelmente de espécie para espécie, em função de parâmetros climáticos e de fatores agronômicos como fertilização, irrigação, colheita e, especialmente a fase de desenvolvimento da planta na época da colheita. Muitas plantas existem sob vários fenótipos, isto é, diferindo na sua aparência e diversidade qualitativa e quantitativa, geralmente detectada na composição do óleo essencial obtido (Kerrola et al., 1994).

O linalol, o constituinte majoritário do óleo de manjericão, tem sido largamente usado como composto de partida para várias sínteses importantes, como a do acetato de linalila, e testado como acaricida, bactericida e fungicida. $\mathrm{Na}$ medicina tem sido aplicado com sucesso como sedativo e, atualmente estão sendo analisadas suas propriedades anticonvulsivas. Assim, o linalol possui larga aplicação em várias áreas do conhecimento humano, sendo necessária sua produção em quantidades sempre crescentes (Radünz, 2004). Estudos recentes têm demonstrado ser possível produzir manjericão com óleo essencial rico em linalol. Isto significa novas oportunidades para pequenos produtores e possibilidades de geração de renda (Maia, 2005). 
Estudos sobre aspectos agronômicos do manjericão no Brasil são muito escassos, apesar de apresentar-se como alternativa e fonte de renda para os proprietários de pequenas áreas. Dentre as necessidades primárias de estudo temse a adubação mineral e/ou orgânica e as populações de plantas que podem contribuir para a maior produção de biomassa e de metabólitos secundários (Ramos et al., 2004).

A cama de frango é uma boa fonte de nutrientes, especialmente de nitrogênio, e quando manejada adequadamente, pode suprir parcial ou totalmente, o fertilizante químico. Além do benefício como fonte de nutrientes, o seu uso adiciona matéria orgânica que melhora os atributos físicos do solo, aumenta a capacidade de retenção de água, reduz a erosão, melhora a aeração e cria um ambiente mais adequado para o desenvolvimento da flora microbiana do solo (Blum et al., 2003).

Diante da necessidade de informações a respeito do cultivo e da produção de óleo essencial este trabalho teve por objetivo avaliar o rendimento e a qualidade do óleo essencial de genótipos de manjericão em função de níveis de adubação orgânica em plantio de inverno, sob irrigação.

\section{MATERIAL E MÉTODOS}

O experimento foi conduzido a campo na Fazenda Experimental do Glória (18 $57^{\circ}$ 'S e $48^{\circ} 12^{\prime}$ W) em Uberlândia$\mathrm{MG}$, de 21 de maio a 7 de outubro de 2005. A temperatura média anual teve mínima de $18^{\circ} \mathrm{C}$ e máxima de $26^{\circ} \mathrm{C}$, umidade relativa do ar com média anual de $75 \%$, precipitação anual de $1274,18 \mathrm{~mm}$, com períodos de seca e chuva bem definidos. $\mathrm{O}$ solo pertence à classe Latossolo Vermelho Distrófico textura média fase cerrado (EMBRAPA, 1999).

O delineamento experimental adotado foi de blocos ao acaso em esquema fatorial $5 \times 2$, com quatro repetições. Como fonte de nutrientes utilizou-se cinco níveis de cama de frango, sendo $2 ; 4 ; 6 ; 8$ e $10 \mathrm{~kg}$ por $\mathrm{m}^{2}$. A composição química da cama de frango foi: $\mathrm{pH}=$ 7,$98 ; \mathrm{MO}=33,70 \mathrm{~g} \mathrm{dm}^{-3} ; \mathrm{N}=2,20 \mathrm{~g}$ $\mathrm{dm}^{-3} ; \mathrm{P}=14,60 \mathrm{~g} \mathrm{dm}^{-3} ; \mathrm{K}=22,80 \mathrm{~g}$ $\mathrm{dm}^{-3} ; \mathrm{Ca}=24,50 \mathrm{~g} \mathrm{dm}^{-3}$ e $\mathrm{Mg}=6,05 \mathrm{~g}$ $\mathrm{dm}^{-3}$. Foram utilizados dois genótipos de manjericão do programa de melhoramento desta cultura da Universidade Federal de Sergipe, sendo designados Manjericão PI 197442-S3 (genótipo 1) e Manjericão NSL 6421-S3 (genótipo 2). A semeadura foi feita em bandejas plásticas utilizando-se substrato comercial. As plântulas foram repicadas para bandejas de poliestireno expandido de 128 células. O transplantio para o campo foi feito quando as plantas apresentaram três pares de folhas verdadeiras, 30 a 40 dias após a semeadura. $\mathrm{O}$ espaçamento utilizado foi de $30 \mathrm{~cm}$ entre plantas e 60 cm entre linhas. Cada parcela foi composta de quatro linhas de seis plantas, tendo como parcela útil as oito plantas centrais.

As plantas foram irrigadas diariamente pelo sistema de aspersão. Quando necessário foi realizada a capina manual para eliminação de plantas daninhas. Não foi necessário o uso de produtos para controle de pragas e doenças. As colheitas foram realizadas no início da manhã, quando as plantas estavam em pleno florescimento seguindo recomendações de Simon (1995).

Foram avaliadas (a) altura da planta (medida da altura $(\mathrm{cm})$ de três plantas que mais representavam a parcela, utilizando-se a média para representála); (b) comprimento e largura de folha (cm) (obtido de três folhas por parcela escolhidas aleatoriamente e totalmente expandidas); (c) relação comprimento/ largura das lâminas foliares (calculada dividindo-se o comprimento médio pela largura média $(\mathrm{cm})$ das folhas amostradas de cada parcela útil); (d) massa fresca e seca (folhas, caules e inflorescências, cortados a $30 \mathrm{~cm}$ do solo, foram transportados e processados no laboratório, que consistiu em separar o material fresco e seco. A massa fresca foi acondicionada em sacos plásticos e levados ao freezer para posterior análise. Outra parte do material foi levada à estufa com circulação e renovação do ar a $40^{\circ} \mathrm{C}$ até obter peso constante); (e) teor de óleo essencial (\%) (utilizou-se $200 \mathrm{~g}$ de folhas e inflorescências frescas e $75 \mathrm{~g}$ de folhas e inflorescências secas de cada parcela); (f) rendimento de óleo essen- cial ( $\mathrm{L} \mathrm{ha}^{-1}$ ) (foi calculado em folhas e inflorescências).

As extrações foram realizadas através de hidrodestilação com o uso de aparelho tipo Clevenger modificado, utilizando-se amostras de $200 \mathrm{~g}$ de folhas e inflorescências frescas e $75 \mathrm{~g}$ de folhas e inflorescências secas segundo recomendações da Asta (1968). A extração foi realizada através do arraste do óleo essencial pelo vapor d'água, por um período de três horas. Ao final deste período o óleo essencial foi coletado, armazenado em frasco de vidro e realizada a análise da sua composição química; (g) teor de linalol no óleo essencial. As amostras dos óleos essenciais foram analisadas utilizando-se cromatografia gasosa em equipamento Shimadzu QP5000 interfaceada com espectrometria de massas (CG/EM) dotada de coluna capilar DB-5 (30m x 0,25 mm x $0,25 \mu \mathrm{m})$. A identificação dos compostos foi efetuada por comparação de seus espectros de massas com o banco de dados do sistema e literatura (McLafferty \& Stauffer, 1989) e determinaram-se os índices de retenção de Kovats, comparando os mesmos com os da literatura (Adams, 1995).

Para realizar as análises dos efeitos quantitativos utilizou-se um modelo de regressão com uma significância de $5 \%$.

\section{RESULTADOS E DISCUSSÃO}

Nos genótipos PI 197442-S3 e NSL 6421-S3 respectivamente, a altura das plantas variou de 48,6 a $51,2 \mathrm{~cm}$ e de 40,0 a 43,2 cm; o comprimento das folhas variou de 7,4 a 8,3 cm e de 7,2 a $8,5 \mathrm{~cm}$; a largura das folhas variou de 2,9 a 3,4 cm e de 3,9 a 5,0 cm; a relação $\mathrm{C} / \mathrm{L}$ variou de 2,3 a 2,6 cm e de 1,7 a 1,8 $\mathrm{cm}$. Em todas estas variáveis não se encontrou diferença significativa (Tabela 1) entre os genótipos avaliados.

Da mesma forma que nas variáveis anteriores, não ocorreram diferenças significativas para rendimento de óleo essencial (massa fresca e massa seca de folhas e inflorescências) e teor de óleo essencial (massa fresca e massa seca de folhas e inflorescências) nos dois genótipos (Tabela 2). Nos genótipos PI 
Tabela 1. Altura de planta, comprimento, largura e relação comprimento/largura de folhas de manjericão dos genótipos PI 19742-S3 e NSL 6421-S3 (plant height, lenght and lenght/ width relation of basil leaves of the genotypes PI 19742-S3 and NSL 6421-S3). Uberlândia, UFU, 2006.

\begin{tabular}{|c|c|c|c|c|}
\hline $\begin{array}{c}\text { Cama de frango } \\
\qquad\left(\mathrm{kg} \mathrm{m}^{-2}\right)\end{array}$ & $\begin{array}{l}\text { Altura de } \\
\text { planta } \\
\text { (cm) }\end{array}$ & $\begin{array}{l}\text { Comprimento } \\
\text { de folha } \\
(\mathrm{cm})\end{array}$ & $\begin{array}{l}\text { Largura } \\
\text { de folha } \\
\text { (cm) }\end{array}$ & Relação C/L \\
\hline \multicolumn{5}{|c|}{ PI 197442-S3 } \\
\hline 2 & 48,9 & 8,3 & 3,2 & 2,6 \\
\hline 4 & 51,1 & 7,7 & 3,1 & 2,5 \\
\hline 6 & 48,6 & 7,4 & 3,2 & 2,3 \\
\hline 8 & 51,2 & 8,1 & 3,4 & 2,4 \\
\hline \multirow[t]{2}{*}{10} & 50,2 & 7,4 & 2,9 & 2,5 \\
\hline & ns & ns & ns & ns \\
\hline $\mathrm{CV}(\%)$ & 7,36 & 13,95 & 16,82 & 9,39 \\
\hline \multicolumn{5}{|c|}{ NSL 6421-S3 } \\
\hline 2 & 42,3 & 7,3 & 4,0 & 1,8 \\
\hline 4 & 40,0 & 7,9 & 4,4 & 1,8 \\
\hline 6 & 41,2 & 7,2 & 4,3 & 1,8 \\
\hline 8 & 40,2 & 7,4 & 4,2 & 1,7 \\
\hline \multirow[t]{2}{*}{10} & 43,2 & 8,5 & 4,6 & 1,7 \\
\hline & ns & ns & ns & ns \\
\hline $\mathrm{CV}(\%)$ & 8,91 & 8,40 & 14,21 & 5,99 \\
\hline
\end{tabular}

Tabela 2. Teor e rendimento de óleo essencial extraído de folhas e inflorescências frescas e secas de manjericão genótipos PI 19742-S3 e NSL 6421-S3 (content and yield of essential oil extracted from fresh and dry leaves and flowers of basil genotypes PI 19742-S3 and NSL 6421-S3). Uberlândia, UFU, 2006.

\begin{tabular}{|c|c|c|c|c|}
\hline \multirow{2}{*}{$\begin{array}{c}\text { Cama de } \\
\text { frango } \\
\left(\mathrm{kg} \mathrm{m}^{-2}\right)\end{array}$} & \multicolumn{4}{|c|}{ Óleo essencial } \\
\hline & $\begin{array}{l}\text { Teor } \\
(\%)\end{array}$ & $\begin{array}{c}\text { Rendimento } \\
\left(\mathrm{L} \mathrm{ha}^{-1}\right)\end{array}$ & $\begin{array}{l}\text { Teor } \\
(\%)\end{array}$ & $\begin{array}{c}\text { Rendimento } \\
\left(\mathrm{L} \mathrm{ha}^{-1}\right)\end{array}$ \\
\hline & \multicolumn{4}{|c|}{$\begin{array}{l}\text { Massa fresca } \\
\end{array}$} \\
\hline & \multicolumn{2}{|c|}{ PI 197442-S3 } & \multicolumn{2}{|c|}{ NSL 6421-S3 } \\
\hline 2 & 2,28 & 19,76 & 4,02 & 10,61 \\
\hline 4 & 1,99 & 23,29 & 4,45 & 7,95 \\
\hline 6 & 1,83 & 21,29 & 3,87 & 8,01 \\
\hline 8 & 1,43 & 14,30 & 4,17 & 6,00 \\
\hline 10 & 1,79 & 21,66 & 5,05 & 10,49 \\
\hline $\mathrm{F}$ & ns & ns & ns & ns \\
\hline \multirow[t]{3}{*}{ CV (\%) } & 20,30 & 27,98 & 7.67 & 25,29 \\
\hline & \multicolumn{4}{|c|}{$\begin{array}{l}\text { Massa seca } \\
\end{array}$} \\
\hline & \multicolumn{2}{|c|}{ PI 197442-S3 } & \multicolumn{2}{|c|}{ NSL 6421-S3 } \\
\hline 2 & 1,70 & 19,73 & 4,10 & 10,81 \\
\hline 4 & 1,52 & 23,74 & 4,39 & 10,00 \\
\hline 6 & 1,36 & 21,56 & 4,01 & 8,55 \\
\hline 8 & 1,56 & 20,64 & 4,25 & 8,26 \\
\hline 10 & 1,59 & 26,49 & 5,17 & 11,83 \\
\hline $\mathrm{F}$ & $\mathrm{ns}$ & $\mathrm{ns}$ & $\mathrm{ns}$ & $\mathrm{ns}$ \\
\hline CV (\%) & 10,97 & 19,23 & 6,23 & 24,22 \\
\hline
\end{tabular}

197442-S3 e NSL 6421-S3 respectivamente, o teor de óleo essencial de massa fresca de folhas e inflorescências variou de 1,43 a $2,28 \%$ e de 3,87 a $5,05 \%$; o florescências variou de 1,36 a $1,70 \%$ e de 4,01 a $5,17 \%$; e rendimento de óleo essencial de massa seca variou de 19,73 a 26,49 $\mathrm{L} \mathrm{ha}^{-1}$ e 8,26 a 11,83 $\mathrm{L} \mathrm{ha}^{-1}$.

Chaves (2002) observou que com relação às doses de adubo, as duas primeiras épocas de corte (outono e inverno) não apresentaram diferença estatística na produção de folhas de alfavaca cravo (O. gratissimum) devido ao tempo ainda não muito longo para que a planta, uma espécie subarbustiva relativamente grande, após absorver os nutrientes disponibilizados no solo pelos adubos, pudesse produzir biomassa de folha suficiente para haver a diferença estatística, mesmo havendo uma tendência a essa maior produção, de forma crescente, porém pequena. A aplicação de $12 \mathrm{~kg} \mathrm{~m}^{-2}$ de adubo orgânico (cama de frango) produziu 389,84 $\mathrm{g}$ de folhas secas de $O$. gratissimum no outono e na testemunha produziu $326,37 \mathrm{~g}$, com um aumento de $19,45 \%$. No inverno, essa diferença foi de $18,89 \%$, na primavera de $21,05 \%$ e no verão $144,62 \%$.

Segundo o mesmo autor, a disponibilidade, absorção e utilização do $\mathrm{N}$ para a produção de biomassa têm uma tendência de aumento no decorrer do tempo. Esta espécie subarbustiva não consegue nos seus sete primeiros meses de vida apresentar maiores extrações de $\mathrm{N}$, mesmo havendo doses crescentes disponibilizadas, proveniente de um adubo orgânico (cama de frango curtida). Com relação ao rendimento de óleo essencial verifica-se que não houve diferença estatística para ambos os genótipos de manjericão com a adição de doses crescentes de adubo orgânico. De acordo com Chaves (2002) não há na literatura um consenso em relação à resposta do rendimento de óleo essencial frente ao uso de tipos de adubos e muito menos de doses. Para o manjericão são registrados aumentos no teor de óleo essencial em quatro concentrações de NPK, sendo N $\left(0,80,160,240 \mathrm{~kg} \mathrm{ha}^{-1}\right), \mathrm{P}(0,50,100$, $\left.150 \mathrm{~kg} \mathrm{ha}^{-1}\right), \mathrm{K}\left(0,60,120,180 \mathrm{~kg} \mathrm{ha}^{-1}\right)$ mais micronutrientes (Hornok, 1983), ou NPK adicionado ao esterco de aves (Silva et al., 2001). Já Carvalho Filho et al. (2006) verificaram maior rendimento do óleo essencial de manjericão quando a massa fresca de folhas e inflorescências são utilizadas. 
Os resultados desse trabalho referendam a diversidade de outros trabalhos com relação ao teor e rendimento de óleo essencial em espécies aromáticas, nas quais podem ser verificadas várias situações. Gershenzon (1984), em estudo com mais de 100 espécies aromáticas, concluiu que as espécies herbáceas respondiam positivamente ao estresse nutricional, com maior proporção desses compostos, o inverso ocorrendo com espécies arbóreas. A componente adubação não pode estar dissociada de outros componentes que interferem no desenvolvimento da planta (e suas partes vegetais) e no rendimento dos óleos essenciais e seus componentes, devendo ser feita uma análise que inclua com-

Tabela 3. Principais constituintes químicos do óleo essencial de manjericão (main chemical constituents of basil essential oil). Uberlândia, UFU, 2006.

\begin{tabular}{lccc}
\hline \multirow{2}{*}{ Constituinte químico } & \multirow{2}{*}{ IK } & PI 197442-S3 (\%) & NSL 6421-S3 (\%) \\
\cline { 3 - 4 } & & 2,3 & 4,5 \\
1,8-Cineol & 1026 & 60,5 & 64,0 \\
Linalol & 1098 & 9,0 & 8,2 \\
Geraniol & 1249 & 1,7 & 2,8 \\
Calareno & 1321 & 2,9 & 3,8 \\
D-Germacreno & 1484 & & Genótipos \\
\hline
\end{tabular}

$\mathrm{IK}=$ Índice de Kovats.

ponentes bióticos, como a relação da espécie com microorganismos, insetos, outras plantas e as rotas biossintéticas dos compostos produzidos pela planta (Ming, 1992).

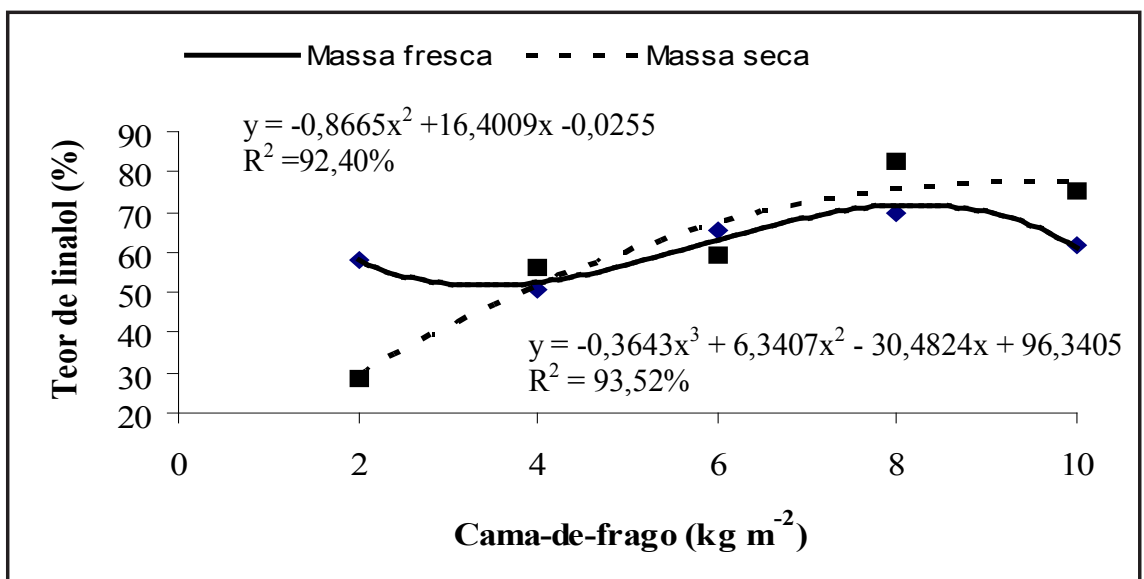

Figura 1. Teor (\%) de linalol no óleo essencial de manjericão do genótipo PI 197442-S3 destilado a partir de folhas e inflorescências frescas e secas, em função da adubação com cama de frango (kg m-2) (linalool content (\%) of the essential oil of basil genotype PI 197442-S3 distilled from fresh and dry leaves and flowers, in function of the fertilization with chicken manure). Uberlândia, UFU, 2006

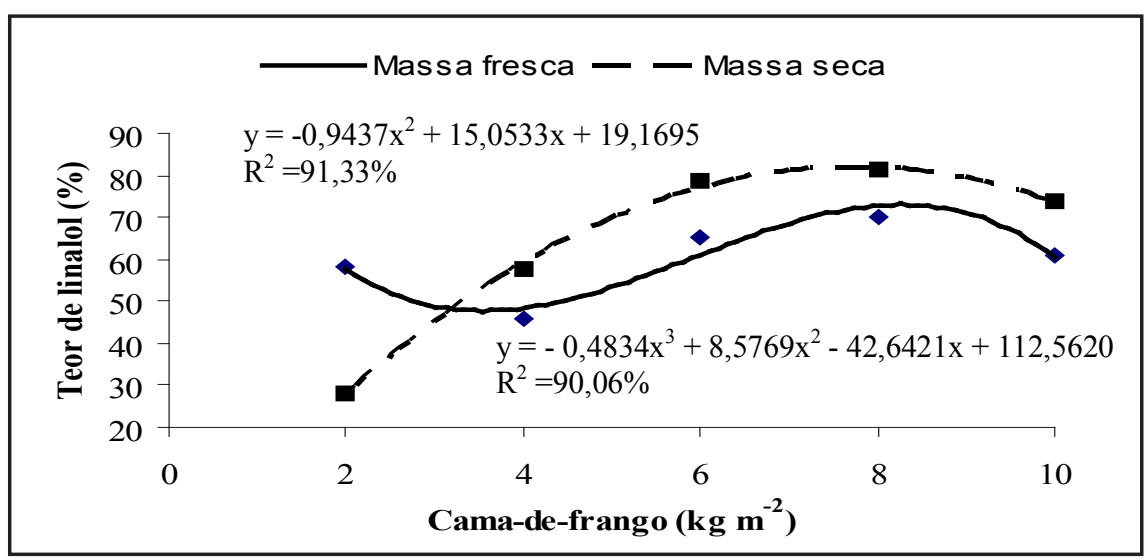

Figura 2. Teor (\%) de linalol no óleo essencial de manjericão do genótipo NSL 6421-S3 destilado a partir de folhas e inflorescências frescas e secas, em função da adubação com cama de frango $(\mathrm{kg} \mathrm{m}-2)$. (Linalool content (\%) of the essential oil of basil genotype NSL 6421-S3 distilled from fresh and dry leaves and flowers, in function of the fertilization with chicken manure). Uberlândia, UFU, 2006.
Com relação aos constituintes químicos presentes no óleo essencial dos genótipos PI 197442-S3 e NSL 6421-S3 de manjericão, os majoritários foram o linalol e o geraniol (Tabela 3). Resultados semelhantes foram obtidos por Fernandes et al. (2004), utilizando a mesma espécie em cultivo hidropônico. $O$ teor de linalol em folhas e inflorescências frescas dos genótipos PI 197442-S3 e NSL 6421-S3 foi estatisticamente influenciado pelas doses de cama de frango (Figuras 1 e 2).

Carvalho Filho et al. (2006) explicam que durante a secagem das plantas de manjericão há um aumento do teor de linalol no óleo essencial. O baixo teor de linalol no óleo essencial, usando $2 \mathrm{~kg} \mathrm{~m}^{-2}$ de cama de frango, deve-se ao fato de que esta quantidade de adubo é pouco para a planta, assim recomenda-se o uso de nutrientes para o metabolismo primário. A partir de $4 \mathrm{~kg} \mathrm{~m}^{-2}$ de cama de frango há nutrientes suficientes para garantir o metabolismo secundário.

O linalol é a substância mais abundante nos dois genótipos estudados, nas massas fresca e seca de folhas e inflorescências dos genótipos PI 197442-S3 (61 e 60\%) e NSL 6421-S3 (60 e 68\%). Carvalho Filho et al. (2006), também verificaram que o linalol $(68 \%)$ é o principal composto presente nas folhas e inflorescências de manjericão. A diferença entre o teor de linalol do material fresco e seco de ambos os genótipos foi provavelmente devido à secagem, sendo que o maior teor no material seco pode ser devido à perda de outros compostos mais voláteis que o linalol durante a secagem.

Diante do exposto, as doses de cama de frango em área de plantio de inverno sob irrigação influenciaram o teor de 
linalol no óleo essencial dos genótipos de manjericão PI 197442-S3 e NSL 6421-S3.

\section{AGRADECIMENTOS}

À CAPES pela concessão da bolsa de mestrado para Tatiane Pereira Santos Morais.

\section{REFERÊNCIAS}

ADAMS RP. 1995. Identification of essential oil components by gas chromatography/ mass spectroscopy. Carol Stream: Allured Publishing Corporation. 469p.

ASTA - American Spice Trade Association. 1968. Official analytical methods of the American Spice Trade Association. Englewood Cliffs, p.8-11.

BLUM LEB; AMARANTE CVT; GÜTTLER G; MACEDO AF; KOTHE D; SIMMLER A; PRADO G; GUIMARÃES L. 2003. Produção de moranga e pepino em solo com incorporação de cama aviária e casca de pinus. Horticultura Brasileira 21: 627-631.

CARVALHO FILHO JLS; BLANK AF; ALVES PB; EHLERT PAD; MELOAS; CAVALCANTI SCH; ARRIGONI-BLANK MF; SILVAMANN R. 2006. Influence of the harvesting time, temperature and drying period on basil (Ocimum basilicum L.) essential oil. Revista Brasileira de Farmacognosia 16: 24-30.
CHAVES FCM. 2002. Produção de biomassa, rendimento e composição de óleo essencial de alfavaca-cravo (Ocimum gratissimum L.) em função da adubação orgânica e épocas de colheita. Botucatu: UNESP. 144p (Tese doutorado).

EMBRAPA - Empresa Brasileira de Pesquisa Agropecuária. 1999. Sistema brasileiro de classificação de solos. Brasília, Embrapa Produção de Informação. Rio de Janeiro: Embrapa Solos. 412p.

FERNANDES PC; FACANALI R; TEIXEIRA JPF; FURLANI PR; MARQUES MOM. 2004. Cultivo de manjericão em hidroponia e em diferentes substratos sob ambiente protegido. Horticultura Brasileira 22: 260-264.

GERSHENZON J. 1984. Changes in the level of plant secondary metabolites under water and nutrient stress. Plenum Press: 334p.

GUENTHER E. 1972. The essential oils. Malabar: Krieger. 427 p.

HORNOK L. 1983. Influence of nutrition on the yield and content of active compounds in some essential oil plants. Acta Horticulturae 132: 239-247.

KERROLA K; GALAMBOSI B; KALLIO H. 1994. Volatile components and odor intensity of four phenotypes of hyssop (Hyssopus officinalis L.). Journal of Agricultural and Food Chemistry 42: 776-781.

LAWRENCE BM. 1992. Advances in Labiatae science. In: HARLEY RM; REYNOLDS T. (eds). The Royal Botanic Gardens Kew. p.406-408.

LORENZI H; MATOS FJA. 2002. Plantas medicinais no Brasil: nativas e exóticas. Nova Odessa: Instituto Plantarum. 544 p.

MAIA NB. 2005. Perfume de manjericão. Disponível em www.fapesp.br/materia. php?data[id_materia] $=2267$. Acessado em 15 de agosto de 2005. Acessado em 15 de agosto de 2005.

McLAFFERTY FW; STAUFFER DB. 1989. The Willey /NBS Registry of Mass Spectral Data. New York: John Willey, p.1-6.

MING LC. 1992. Influência de diferentes niveis de adubação orgânica na produção de biomassa e teor de óleo essenciais de Lippia alba (Mill.) N.E. Br. Verbenaceae. Curitiba: UFPR. 206p (Tese mestrado).

RADÜNZ LL. 2004. Efeito da temperatura do ar de secagem no teor e na composição dos óleos essenciais de guaco (Mikania glomerata Sprengel) e hortelã-comum (Mentha x villosa Huds). 2004. Viçosa: UFV. 90p (Tese doutorado).

RAMOS MBM; VIEIRA MC; ZÁRATE NAH; SIQUEIRA JM; ZIMINIANI MG. 2004. Produção de capítulos florais da camomila em função de populações de plantas e da incorporação ao solo de cama-de-aviário. Horticultura Brasileira 22: 566-572.

SILVA PA; BLANK AF; ARRIGONI-BLANK MF; ALVES PB; SANTOS NETO AL; CARVALHO FILHO JLS; AMANCIO VF. 2001. Efeito da adubação mineral e orgânica e do horário de colheita em manjericão-doce. Horticultura Brasileira 19 (CD-ROM).

SIMON JE. 1995. Basil. West Lafayette: Purdue University. $6 \mathrm{p}$. 